\title{
DESAFIOS E ESTRATÉGIAS IMPLEMENTADAS NA ADOÇÃO DE CRIANÇAS MAIORES E ADOLESCENTES
}

\author{
CHALLENGES AND STRATEGIES IMPLEMENTED IN THE ADOPTION OF \\ OLDER CHILDREN AND ADOLESCENTS
}

RESUMO: A adoção é medida excepcional e irrevogável, à qual se deve recorrer apenas quando esgotados todos os recursos de manutenção da criança ou adolescente na família natural ou extensa. Essa modalidade de constituição familiar ainda é cercada por preconceitos, principalmente quando se trata de adoção de crianças maiores e adolescentes, a chamada adoção tardia. 0 presente estudo teve como objetivo analisar oito casos de adoção de crianças maiores de dois anos e adolescentes para verificar os desafios enfrentados por adotantes e adotandos na adaptação familiar e quais estratégias foram utilizadas para lidar com os mesmos. Realizou-se estudo retrospectivo documental com estudos sociais efetuados após 0 estágio de convivência. Verificou-se que a convivência familiar dos adotantes com os adotandos nos primeiros meses de adaptação foi difícil, no entanto, as estratégias utilizadas, tais como auxílio psicológico familiar, busca por atendimento médico especializado, apoio da família extensa, paciência, reforço positivo sobre a adoção e persistência dos pais para superar as dificuldades contribuíram para o êxito dessas adoções.

PALAVRAS-CHAVE: Adoção; Adoção tardia; Convivência familiar; Adaptação; Estágio de convivência.
ABSTRACT: Adoption is an exceptional and irrevocable measure, which should only be used when all the resources of maintenance of the child or adolescent in the natural or extended family have been exhausted. This modality of family constitution is still surrounded by prejudice, especially when it comes to adoption of older children and adolescents, what is called late adoption. The present study aimed to analyze eight cases of adoption of children over two years old and adolescents to verify the challenges faced by adopters and adoptees in family adaptation and what strategies were adopted to deal with them. A retrospective documentary study was carried out with social studies performed after the cohabitation stage. It was verified that the familiar coexistence of adopters with adoptees in the first months of adaptation was difficult, however, strategies used such as family psychological help, search for specialized medical care, extended family support, patience, positive reinforcement on adoption and persistence of parents to overcome the difficulties contributed to the success of these adoptions.

KEYWORDS: Adoption; Late Adoption; Family Life; Adaptation; Probationary Period. ANGELITA DA COSTA
PEIXOTO $^{1}$
ANDRÉIA ISABEL
GIACOMOZZI $^{2}$

\section{ANDRÉA BARBARÁ DA SILVA BOUSFIELD²}

\section{BRUNA BERRI ${ }^{2}$}

\section{JULIANA GOMES FIOROTT $^{2}$}

\author{
${ }^{1}$ Poder Judiciário de \\ Santa Catarina, \\ Florianópolis/SC, Brasil \\ ${ }^{2}$ Universidade Federal de \\ Santa Catarina - UFSC, \\ Florianópolis/SC, Brasil
}

\section{INTRODUÇÃO}

Segundo o Estatuto da Criança e do Adolescente (1990), a adoção é uma medida excepcional e irrevogável, à qual se deve recorrer apenas quando esgotados todos os recursos de manutenção da criança ou adolescente na família natural (biológica) ou extensa (tios, avós, etc). A adoção é uma medida de proteção e tem por finalidade encontrar uma família para uma criança ou adolescente que teve seu vínculo rompido com os familiares consanguíneos (Santos et al., 2003). Historicamente, essa me- 
dida tinha como propósito suprir necessidades dos adultos que, por algum motivo, não podiam conceber filhos biológicos. No entanto, a noção e os objetivos da adoção têm se transformado ao longo dos anos, e na atualidade ela pode ser entendida como um modo legítimo para o exercício da parentalidade (Silva, 2009; Trindade, 2010).

Esta modalidade de constituição familiar ainda é um assunto polêmico, pois divide opiniões e remete a questões íntimas como a infertilidade, por exemplo, que tem sido apontada como principal motivação para o projeto adotivo (Giacomozzi, Nicoletti, \& Godinho, 2015; Gondim et al., 2008; Levinzon, 2004; Weber, 2003). Também é uma temática coberta de muitos preconceitos, principalmente a chamada adoção tardia (Goes, 2014; Weber \& Cornélio, 1994; Weber \& Gagno, 1995).

A adoção tardia pode ser compreendida como a adoção de crianças maiores, que já têm a capacidade de se perceberem de modo diferenciado do mundo e do outro. Isto é, aquela criança que não é mais um bebê e possui certa independência do adulto para realização da satisfação de suas necessidades básicas. Pode-se considerar, assim, a faixa etária entre dois e três anos como um limite entre a adoção entendida como convencional e a chamada tardia (Vargas, 1998). De acordo com a cartilha "Passo a passo para a adoção", promovida pela Associação dos magistrados brasileiros (2014), é chamada de adoção tardia aquela de crianças acima de dois anos, compreendendo até o período da adolescência.

No entanto, é necessário refletir acerca do termo adoção tardia, que pode remeter a uma ideia de algo fora de um tempo adequado e assim reforçar crenças de que a adoção é prerrogativa de recém-nascidos (Carvalho \& Ferreira, 2000; Mello \& Luz, 2016).
Diante desse entendimento, este trabalho irá utilizar o termo adoção de crianças maiores.

Segundo dados do relatório estatístico de pretendentes à adoção no Brasil, o perfil mais desejado por quem está aguardando pela adoção é de crianças de até 3 anos de idade, configurando 19,08\% de um universo de 43865 pretendentes habilitados no cadastro nacional de adoção. Com relação a crianças até 8 anos, o cadastro aponta para $2,74 \%$ dos pretendentes que aceitariam adotar nesta idade (Cadastro Nacional de Adoção, 2018). Apesar das diversas campanhas dos tribunais de justiça brasileiros visando à promoção de uma nova cultura da adoção, que contemple a adoção de crianças maiores, tais dados denotam o quanto a adoção dessas crianças ainda é pouco praticada ou desejada pelos pretendentes.

Estudos têm apontado para sentimento de medo experimentado por pretendentes à adoção relacionado a adotar crianças maiores por possíveis dificuldades na educação (Weber et al., 1994; Weber \& Cornélio, 1994; Weber \& Gagno, 1995) ou ainda receio de adotar crianças institucionalizadas pelos maus hábitos que trariam consigo. Da mesma forma, pesquisas apontaram para a preferência dos brasileiros pela adoção de bebês, do sexo feminino (Giacomozzi, Nicoletti, \& Godinho, 2015) e da mesma cor da pele dos candidatos (Costa \& Rossetti-Ferreira, 2007; Mariano, 2004; Vargas, 1998).

Nesse sentido, quando decididos pela adoção de uma criança maior, os pretendentes precisam refletir acerca do projeto adotivo e da capacidade de desenvolver vínculos afetivos com uma criança mais velha, lidar com o preconceito relacionado à crença de que crianças maiores serão "mais problemáticas" e ainda considerar que a trajetória de vida já percorrida pela 
criança/adolescente possa vir a desencadear problemas futuros (Mello \& Luz, 2016). Ainda que, independentemente da idade da criança, pais adotantes tenham que passar por reflexões acerca do projeto adotivo, a adoção de uma criança maior difere-se da adoção de bebês, em que muitas vezes idealiza-se que o bebê não tenha uma história prévia e que a vinculação será mais facilmente desenvolvida (Weber, 2008).

Com relação à adoção de crianças maiores, estudos apontam uma associação desse fator a um maior índice de interrupções na adoção, as chamadas devoluções (Festinger, 2012; Smith et al., 2006). Em pesquisa realizada em Portugal acerca das concepções de parentalidade, identificou-se que quanto maior a idade da criança quando realizada a adoção, maior a complexidade da concepção de parentalidade para os pais adotivos, no que diz respeito à capacidade metacognitiva demonstrada pelos pais na compreensão de si próprios, dos filhos e da relação entre ambos (Silva, Nunes, \& Almeida, 2017). Isso requer a atenção para a importância de um acompanhamento qualificado na fase de adaptação, a nova configuração familiar, visando à minimização dos possíveis desafios desse momento.

Ainda que a legislação brasileira indique que a adoção é uma medida irrevogável, não sendo possível a devolução, durante o período de estágio de convivência, em que está ocorrendo a aproximação, vinculação e, por fim, a efetiva ida da criança/adolescente para o novo ambiente familiar, a adoção propriamente dita ainda não é concretizada. Nesta situação, juridicamente, o processo não foi finalizado, logo, pode ser interrompido pelos postulantes à adoção ou pelo poder judiciário. Após o processo findado, caso os pretendentes manifestem o desejo pela desvinculação da criança/adolescente, deve ser feito o ajuizamento de uma nova ação processual, neste caso, de destituição do poder familiar dos pais adotivos, resultando um duplo abandono. Em alguns tribunais, quando essa prática ocorre, tem-se imputada multa devido aos prejuízos psicológicos que essa ação ocasiona (Dias, 2005; Riede \& Sartori, 2017).

Nesse sentido, são diversos e complexos os fatores imbricados no período da adaptação e vinculação familiar após a chegada de um filho por adoção. Essa etapa pode ser entendida como sensível, visto que, em geral, os adotantes procuram uma criança ainda muito idealizada, assim como as crianças e adolescentes também buscam a família perfeita (Alonso, 2012; Levy, Pinho, \& Faria, 2009; Simmel, 2007; Sturgess \& Selwyn, 2007; Weber, 2003).

Quando o novo filho finalmente chega, ele traz consigo sua história e vínculos anteriores, com tantos conteúdos quanto maior for a sua idade (Alonso, 2012). Ao longo desse processo, pais e filhos podem encontrar dificuldades para sustentar o projeto da adoção e o ato de devolução da criança representa, com frequência, uma saída para os incontornáveis conflitos experimentados nesta relação (Ghirardi, 2009).

No que diz respeito à regulamentação para a adoção no Brasil, ela é prevista pela Lei ${ }^{\circ} 12010 / 09$ e preconiza que, após o período de preparação psicossocial, jurídica e avaliação, situações orientadas pela equipe técnica da Justiça da Infância e da Juventude, os pretendentes habilitados deverão ser inseridos em cadastros Estaduais e nacionais de adoção. O cadastro desenvolvido pelo Conselho Nacional de Justiça chama-se Cadastro Nacional de Adoção e nele encontram-se dados de crianças e adolescentes em 
condições de serem adotados e de pessoas ou casais habilitados à adoção. O cadastro possibilita um acesso público para visualizar relatórios estatísticos de pretedentes (número de pretendentes, UF, perfil desejado) e de crianças (número de crianças, UF, idade, sexo, raça, etc). No entanto, os dados que dizem respeito ao número de adoções concretizadas ou que não foram finalizadas por desistência dos pretendentes são de acesso restrito.

Nessa perspectiva, para a entrada de um pedido de adoção, a legislação prevê uma capacitação para os pretendentes, além de avaliações psicológica e social. Para o acompanhamento pós-adoção, é indicado um período de estágio de convivência que deve ser realizado sob o acompanhamento dos técnicos e das técnicas do poder judiciário ou do serviço de acolhimento institucional (Lei $\mathrm{n}^{\circ}$ 12010, 2009). A partir da ocorrência do estágio de convivência familiar, é realizada uma nova avaliação pela equipe técnica (assistentes sociais e/ou psicólogos), com o objetivo de verificar como está o processo de adaptação da atual configuração familiar. A legislação preconiza que dessa avaliação deverá ser elaborado um relatório detalhado acerca desse estágio.

Diante disso, o presente estudo objetivou analisar os estudos sociais elaborados pelas assistentes sociais de uma Vara de Infância e Juventude, na qual tramitam os processos de adoção no Brasil. O período que abrange o estudo, em uma comarca do Sul do Brasil, foi de um ano, após o estágio de convivência. A amostra foram famílias que adotaram crianças maiores de 2 anos de idade. Nesse contexto, buscou-se identificar os desafios enfrentados por adotantes e adotandos na adaptação familiar, bem como identificar as estratégias utilizadas para equacioná- -los a fim de problematizar e fornecer subsistidos para a literatura a respeito deste estágio de convivência

\section{MÉTODO}

Tratou-se de um estudo documental, retrospectivo, descritivo e exploratório, conduzido sob o enfoque qualitativo de pesquisa. Como estratégia metodológica foi adotado o estudo de caso (Peres \& Santos, 2005). Foram explorados oito casos de adoção de crianças maiores realizados em uma Vara da Infância do Poder Judiciário no Sul do Brasil. Os documentos utilizados como fonte de informação foram os estudos sociais de oito processos judiciais de adoção de crianças maiores de dois anos de idade. O acesso aos processos judiciais foi autorizado pelo juiz responsável da Vara, por meio de assinatura de uma declaração de conhecimento e de autorização da pesquisa. Como procedimento ético, para garantir o sigilo e o anonimato das pessoas envolvidas, os nomes utilizados nos relatos de caso são fictícios.

Os dados foram analisados por meio de análise de conteúdo categorial-temática (Bardin, 2000), na qual foram respeitadas as seguintes etapas: pré-análise, exploração do material, tratamento dos resultados, inferência e interpretação.

\section{Participantes}

Dos oito estudos sociais, seis tinham como requerentes casais heterossexuais, um era casal homossexual (sexo masculino) e um deles um homem solteiro homossexual. No que se refere à raça/cor dos adotantes, a sua totalidade era branca. A média de idade dos adotantes foi de 43 anos e 
salário/renda com uma média de $\mathrm{R} \$$ $3.490,00$. No que tange à escolaridade, dos 15 adotantes, oito possuíam nível superior completo, dois tinham pós-graduação, dois o ensino médio e apenas um o ensino médio incompleto, sendo que um estudo social não apresentava este dado. Quatro famílias tinham filhos biológicos ou adotivos anteriores à adoção e quatro não possuíam filhos.
Quanto ao perfil das crianças e/ou adolescentes, de acordo com a Tabela 1 , observou-se que cinco casos referiram-se a grupo de irmãos. Um com três crianças e os demais com duas. A idade variava entre onze meses a quinze anos de idade. Das 14 crianças adotadas, cinco eram do sexo masculino e nove feminino. No que diz respeito à etnia, apenas um caso tratava de crianças pardas, as demais eram brancas.

Tabela 1 - Perfil das crianças adotadas

\begin{tabular}{|c|c|c|c|c|c|}
\hline $\begin{array}{c}\text { Estudo } \\
\text { social }\end{array}$ & Idade & Sexo & Etnia & Adotandos & $\begin{array}{c}\text { Filhos antes da } \\
\text { adoção }\end{array}$ \\
\hline 1 & 7 anos & Feminino & Branca & Uma & 2 biológicos \\
\hline \multirow[b]{2}{*}{2} & 7 anos & Feminino & Mulata & \multirow{2}{*}{$\begin{array}{l}\text { Grupo de } \\
\text { duas irmãs }\end{array}$} & \multirow{2}{*}{0} \\
\hline & 11 meses & Feminino & Mulata & & \\
\hline 3 & 4 anos & Feminino & Branca & Uma & 2 biológicos \\
\hline \multirow[b]{2}{*}{4} & 15 anos & Masculino & Branca & \multirow{2}{*}{$\begin{array}{c}\text { Grupo de } \\
\text { dois irmãos }\end{array}$} & \multirow{2}{*}{0} \\
\hline & 9 anos & Feminino & Branca & & \\
\hline \multirow{3}{*}{5} & 7 anos & Feminino & Branca & \multirow{3}{*}{$\begin{array}{l}\text { Grupo de } \\
\text { três irmãs }\end{array}$} & \multirow{3}{*}{1 adotivo } \\
\hline & 3 anos & Feminino & Branca & & \\
\hline & 1 ano & Feminino & Branca & & \\
\hline \multirow[b]{2}{*}{6} & 7 anos & Masculino & Branca & \multirow{2}{*}{$\begin{array}{c}\text { Grupo de } \\
\text { dois irmãos }\end{array}$} & \multirow{2}{*}{2 biológicos } \\
\hline & 5 anos & Feminino & Branca & & \\
\hline \multirow[b]{2}{*}{7} & 9 anos & Masculino & Branca & \multirow{2}{*}{$\begin{array}{c}\text { Grupo de } \\
\text { dois irmãos }\end{array}$} & \multirow{2}{*}{0} \\
\hline & 4 anos & Masculino & Branca & & \\
\hline 8 & 4 anos & Masculino & Branca & Uma & 0 \\
\hline
\end{tabular}




\section{RESULTADOS}

A partir da análise dos dados, encontraram-se duas grandes categorias, denominadas:

1. Dificuldades na adaptação familiar entre pais e filhos.

2. Estratégias de enfrentamento para nova configuração familiar.

A categoria 1 foi dividida em subcategorias temáticas que foram: falta de limites e/ou estímulos (8); comprometimento da saúde física e/ou psicológica (7); comportamento sexualizado (5); dificuldade de relacionamento com os irmãos (3); afastamento de familiares e/ou amigos (3); relação com a família biológica/bagagem histórica (3); sobrecarga de tarefas (3); distanciamento do casal (2).

\section{Subcategoria 1 - Falta de limites e/ou estímulos}

Esta subcategoria aparece em todos os relatórios ou estudos sociais analisados como fonte de preocupação e conflitos entre os pais e filhos, sobretudo nos primeiros meses da convivência. A agressividade, o hábito de se utilizar de palavrões e "birras" para lidar com contrariedades, como se observa a seguir por meio de alguns exemplos:

... teve de se impor e lidar com choro e manha para quase tudo. Pentear o cabelo era motivo para choro, por exemplo. Como a criança urinava na fralda à noite, o casal passou a acordá-la durante esse período para ir ao banheiro. O que era outro incômodo para a criança. Com o tempo, o choro passou de todo o dia para uma semana sim outra não. (Estudo Social 2)

A falta de concentração, de estímulos, pouca ou nenhuma instrução formal, falta de noção de higiene e cuidados pessoais, o enfrentamento e a desobediência, a resistência a regras e limites, hábitos alimentares diferenciados e/ou equivocados, são outras situações vivenciadas nos casos analisados e relatados pelos adotantes em relação aos adotandos quando do início da vida em comum, como se percebe ao ler o trecho destacado:

... quando chegou, a criança falava muitos palavrões, não se concentrava para brincar, ficando agitada. Se masturbava e, por isso, buscava se isolar para ficar se tocando, não conhecia as letras, não gostava de estudar, não obedecia às regras e era agressiva com as irmãs. (Estudo Social 1)

Em dois casos acrescentam-se duas outras características: no primeiro deles, houve, por parte da criança, uma grande necessidade de falar sobre a vivência anterior, quando estava sob os cuidados da família biológica. A naturalidade com que se reportava a episódios envolvendo drogas, sexualidade e ilícitos trouxe angústia e medo aos guardiões. No segundo, o que caracterizou o principal desafio à adaptação foi o fato de a criança expressar verbalmente o seu desejo por uma família composta de pai e mãe. Idealizava a existência de uma genitora, coisa que não aconteceria, pois o adotante havia, desde o primeiro momento de aproximação, deixado claro sua orientação sexual, além de estar solteiro naquele momento.

\section{Subcategoria 2 - Comprometimento da saúde física e/ou psicológica}

Esta categoria foi a segunda em número de ocorrências, também causa de transtornos à adaptação familiar, todavia se diferencia da primeira por estar 
mais atrelada à adaptação do adotante ao desempenho de seu novo papel social, mais precisamente no exercício da parentalidade do que propriamente na convivência com o adotando.

A necessidade de avaliação e intervenção médica e/ou psicológica é algo que aflige os pais e os faz temer pelo bem-estar dos filhos. Anemia, déficit de crescimento, alterações hormonais, problemas pulmonares como bronquite e asma, desidratação e desnutrição, problemas oftalmológicos e dentários, toxoplasmose congênita, enurese noturna, medos, ansiedade e insegurança foram problemas de saúde observados nas amostras selecionadas, conforme se verifica a seguir:

$A$ adotante deu continuidade ao tratamento odontológico iniciado pela criança na Casa Lar e teve bastante trabalho para auxiliar a filha a lidar com o trauma que ela tinha frente àquele profissional depois de ter sido submetida a uma extração dentária (Estudo Social 2).

Essa nova realidade e exigência natural do adotando acarretaram insegurança e aflição nos primeiros momentos da convivência, sobretudo para os pais que não possuíam filhos anteriores à adoção realizada. Os relatos coletados evidenciam que, apesar da insegurança inicial ocorrida devido ao comprometimento da saúde física e/ou psicológica nos casos em tela, tais dificuldades são encaradas como algo natural e passíveis de solução, sendo algo possível de contornar.

\section{Subcategoria 3 - Comportamento sexualizado}

Essa categoria foi encontrada em cinco dos oito relatórios ou estudos sociais analisados e traz um dado muito preocupante, pois revela o número elevado de crianças e/ou adolescentes que foram vítimas de algum tipo de abuso sexual nas famílias de origem. De todas as categorias, foi aquela que mais preocupou os adotantes, deixando-os angustiados, sem saber de que forma agir para lidar com o problema.

Muitos se disseram despreparados para lidar com algo que não deveria fazer parte da realidade de crianças e/ ou adolescentes não somente por se tratar de uma violência mas, também, por expô-las ao sexo, assunto que ainda é encarado como uma preocupação para muitas pessoas, como se pode observar por meio do seguinte extrato:

Afirmou que teve muito receio do comportamento sexualizado de Margarida, e chegou a pensar em procurar o Fórum em busca de auxílio. (Estudo Social 5)

Além das lesões físicas que esse tipo de violência ocasiona, a possibilidade de vir a adquirir alguma doença sexualmente transmissível (DSTs), as sequelas emocionais e distúrbios sexuais que aparecem se configuram como um grande desafio aos adotantes. A incerteza que acompanha o adotante ao se reportar para o futuro e se perguntar se a educação será suficiente para sanar os prejuízos causados pela violência foi uma inquietação manifestada por meio da frase que segue, referindo-se à criança:

... foi exposta a toda sorte de riscos, inclusive de cunho sexual e, por isso, ele sofre por pensar que talvez não consiga incutir os valores que entende serem importantes para a formação de seu caráter e ela acabar sofrendo, assim como ele e a esposa. (Estudo Social 1) 
Subcategoria 4 - Dificuldades de relacionamento com os irmãos

Dos oito estudos sociais, três apontaram dificuldades de relacionamento da criança adotada com os irmãos que foram identificados como sendo tanto os biológicos (no caso de adoção de grupo de irmãos), como aqueles cujo vínculo aconteceu depois da medida de proteção (famílias que já possuíam filhos). É necessário enfatizar que, dos oito casos, em quatro deles havia filhos anteriores à adoção e em três não havia filhos, no entanto, foram adotados grupos de irmãos, perfazendo um total de sete casos em que aparecem o relacionamento fraterno.

A competição, a rivalidade, os ciúmes, as brigas, os desentendimentos, a mudança de comportamento, foram alguns dos sentimentos e/ou atitudes verificados pelos adotantes quando se referiram ao relacionamento dos filhos no exercício da fratria, como se vê por meio do trecho que segue:

... afirmou que Rosa foi quem mais se ressentiu com a presença de Violeta num primeiro momento pois, era a caçula e com um maior contato com a mãe. Além disso, a irmã mais velha formou um vínculo de cumplicidade com a recém-chegada, excluindo-a. Observa que a filha de carinhosa, passou a ser um pouco agressiva. (Estudo Social 1)

\section{Subcategoria 5 - Afastamento de familiares e/ou amigos}

Esta categoria está presente em três estudos sociais e representa a realidade enfrentada pelas famílias. Uma delas viu um familiar se afastar da convivência diária depois de efetivada a adoção. Outra teve que lidar com o preconceito e todas referiram o distanciamento de amigos. O relato extraído dos estudos sociais exemplifica:

Outra mudança que percebeu foi em relação ao ciclo de amigos, que não os convidam mais para sair como antigamente. Apesar de sentir falta, afirmou que entende que hoje eles formam uma família e têm outras prioridades e objetivos. (Estudo Social 2 )

Subcategoria 6 - Relação com a família biológica/bagagem histórica

Esta categoria, encontrada em três dos oito casos analisados, se refere aos problemas advindos da maneira com que os adotandos e adotantes lidam com assuntos que envolvem a proximidade com a família biológica ou as informações trazidas pelas crianças e /ou adolescentes sobre sua vida pregressa junto aos genitores e família extensa. Dependendo da forma como é abordado esse assunto, pode ser fonte de preocupações e dificuldades no relacionamento, como demonstra o trecho a seguir:

Costuma falar sobre a família biológica e menciona o nome da mãe principalmente quando quer conseguir algo dos guardiões. Nos momentos de contato com os parentes ela fica confusa pois eles, por ignorância, cogitam a possibilidade dela voltar para a genitora. (Estudo Social 1)

\section{Subcategoria 7 - Sobrecarga de tarefas}

A presente categoria foi verificada em três estudos sociais e revela o acúmulo de tarefas diárias dos adotantes relacionado não apenas com os cuida- 
dos com os adotandos, mas, também, aos demais afazeres da casa e do trabalho. Nos relatos, que contemplam três casais, aparecem as desigualdades e responsabilidades que, com a chegada do novo membro da família, tornaram-se mais prementes e acabaram sobrecarregando um dos cônjuges, geralmente a mulher. De acordo com o trecho abaixo,

como o marido passa a semana viajando, ela é quem se responsabiliza com tudo o que diz respeito às filhas. Médico, dentista, escola, enfim, todas as necessidades delas são supridas pela figura materna. (Estudo Social 5)

Subcategoria 8 - Distanciamento do casal

Dos oito estudos sociais dois mencionaram ter havido distanciamento do casal depois da chegada dos filhos por adoção. O tempo exíguo dispensado ao relacionamento conjugal devido ao acúmulo de responsabilidades e a necessidade de se privilegiar a parentalidade nos primeiros meses do estágio de convivência foram dificuldades apontadas. Os casais sentiram não só o distanciamento entre os cônjuges, como perceberam modificação no seu comportamento e na forma com a qual se relacionavam antes da adoção.

Observou-se também que os casais tinham consciência desse fato. Um deles expressou a vontade de modificar tal realidade, mas se via impossibilitado pela demanda com os filhos que ainda era a prioridade naquele momento. $\mathrm{O}$ outro, por sua vez, buscava alternativas para resgatar a conjugalidade, porém tinha que lidar com as restrições impostas pelas responsabilidades assumidas:
... disse que o tempo para o casal diminuiu muito. Além disso, percebeu que o marido está mais ríspido com ela, mas não costumam brigar. Asseverou que tanto ela quanto o marido estão conscientes da necessidade de se voltarem mais um para o outro e estão aguardando o retorno das filhas às aulas, para terem um tempo maior para si mesmos. (Estudo Social 2)

No que diz respeito à categoria denominada "Estratégias utilizadas pelos casais para lidar com as situações apresentadas", foram identificadas seis subcategorias: imposição de regras e limites (8); busca por atendimento médico especializado (7); realização de psicoterapia (4); utilização de castigos e palmadas (4); reforço positivo sobre a adoção (4); apoio da família extensa (3).

A imposição de regras e limites é algo que aparece de forma unânime. Lidar com crianças maiores de dois anos de idade e/ou adolescentes implica o exercício de reeducar, eis que, diferentemente dos bebês, elas já assimilaram algum tipo de orientação, quer na família consanguínea, na instituição de acolhimento ou em família substituta:

Depois, os dois meses seguintes foram de impor limites, regras e de adequar as irmãs à nova realidade e para que as três meninas incorporassem a quarta ao grupo. (Estudo Social 5)

Estabelecer regras e limites nesses casos não é simplesmente adaptar o adotando a outras normas, mas convencê-lo de que muito daquilo que foi aprendido não será mais utilizado porque não cabe na sua nova realidade, uma vez que sua educação agora

\section{Juliana}


está sendo baseada em valores e regras defendidas e cultivadas pelos adotantes, as quais passam a prevalecer. $\mathrm{Na}$ busca por esse objetivo, a paciência, a dedicação e a persistência aparecem como estratégia fundamental para a adaptação. O equilíbrio emocional é, portanto, condição primária para que a mesma aconteça:

Reeducar as filhas principalmente a Margarida foi um trabalho de paciência e persistência, não sabia o que era ser cuidada e a guardiã teve que desmistificar todo um entendimento equivocado aprendido ao longo de seus sete anos de vida. (Estudo Social 5)

Observou-se que em quase sua totalidade houve a existência da categoria do comprometimento físico e/ou psicológico em relação à criança ou ao adolescente adotado. Os adotantes buscaram atendimento especializado e solução para essas questões. No caso das doenças físicas, um atendimento com resposta mais imediata; e das psicológicas, por meio de acompanhamento sistemático de uma forma mais gradativa devido à sua especificidade, conforme pode ser exemplificado a seguir por meio de um dos extratos retirados dos estudos sociais. $\mathrm{O}$ relato demonstra essa categoria:

Foi encaminhada a um endocrinologista depois que seus exames hormonais apontaram alteração. Foi preciso iniciar atendimento médico, $o$ atendimento odontológico é particular quando, por alguma razão, não pode ser feito na policlínica. (Estudo Social 2)

$\mathrm{O}$ atendimento psicológico também aparece como forma de auxiliar a família a lidar com a adoção propria- mente dita. Dos sete casos analisados em que se observou a necessidade de atendimento médico ou psicológico, quatro fizeram uso de psicoterapia. Um deles teve a preocupação de buscar esse atendimento antes mesmo de iniciar o processo de habilitação no cadastro para adoção, buscando se preparar e entender seus objetivos, suas possibilidades e suas limitações à paternidade. Tratava-se de um homem solteiro que fez a seguinte observação no estudo social analisado:

Quando senti que já era tempo de construir uma família, procurei fazer terapia para trabalhar a ideia e poder discutir todas as implicações dessa decisão. (Estudo Social 4)

Em dois outros casos, os guardiões foram orientados pela assistente social forense a procurar o dito atendimento devido à demanda identificada por ocasião do estudo social no processo de adoção. E o último, sentindo a necessidade, procurou por um profissional por iniciativa própria e iniciou o acompanhamento psicológico antes mesmo de ter sido atendido pelo assistente social forense para a confecção do estudo social no processo de adoção:

A educação da infante em tela tem tido como base uma enorme carga de equilibrio emocional por parte dos requerentes, revelou que foi preciso levá-la para atendimento psicológico. (Estudo Social 1)

Em quatro dos oito casos analisados, a utilização de castigos e palmadas foi observada como uma prática frequente, aparecendo como algo cultural, aplicada pelos adotantes como forma de obter a obediência por parte dos adotandos: 
Acrescentou que a criança tenta en-

frentar os guardiões e, quando isso acontece, ela é colocada de castigo em uma cadeira para pensar ou algo the é retirado, como a bicicleta. No início da convivência, afirmou que teve de aplicar-lhe palmadas para se fazer obedecer. (Estudo Social 1)

O reforço positivo sobre a adoção realizada aparece em metade dos casos analisados. É comum o adotando se sentir inseguro, principalmente nos primeiros meses da convivência. Ouvir que foi escolhido, que é querido pelo adotante, não só oportuniza confiança, como aproxima emocionalmente os envolvidos:

... ocasião em que reforçaram que "agora são seus pais" e que não haverá reversão dessa decisão. Tal postura trouxe segurança à criança que não cogitou mais a possibilidade de retorno para o serviço de acolhimento elou para a família biológica nos momentos em que é contrariado. (Estudo Social 7)

A família extensa, composta de avós, tios, primos, irmãos, cunhados, etc., também possui um papel importante na adaptação. Em três dos oito casos os adotantes verbalizaram o quanto foi necessário o apoio dos parentes nesse processo, quer pela necessidade de obter respaldo de suas ações na experiência dos mais velhos, quer pelo simples fato de se sentirem apoiados no exercício da paternidade/maternidade. É o que observamos com o extrato a seguir:

O casal foi unânime ao afirmar que todos apoiaram e estão felizes com a vinda de Cravo. A criança foi batizada e os padrinhos são apegados demais a ele. (Estudo Social 8)

\section{DISCUSSÃO}

Este estudo teve como objetivo fazer uma análise de oito estudos sociais efetuados em processos de adoção de crianças maiores, buscando identificar os desafios enfrentados por adotantes e adotandos na adaptação familiar, bem como identificar as estratégias utilizadas para equacioná-los.

Foram observadas oito subcategorias referentes às dificuldades na adaptação familiar entre pais e filhos: a falta de limites e/ou estímulos das crianças, comprometimento da saúde física e/ ou psicológica, comportamento sexualizado dos filhos, dificuldade de relacionamento com os irmãos, afastamento dos adotantes de familiares e/ ou amigos, relação com a família biológica/bagagem histórica, sobrecarga de tarefas e distanciamento do casal. E seis relacionadas às estratégias utilizadas pelos casais para lidar com as situações apresentadas: necessidade de impor regras e limites, busca por atendimento médico especializado, realização de psicoterapia, utilização de castigos e palmadas, reforço positivo e busca de apoio da família extensa.

No que tange aos sentimentos vivenciados pelas crianças recém-inseridas em famílias substitutas, angústia, insegurança, medo, saudade, ansiedade, tristeza, alegria, dúvida, revolta são alguns exemplos que demonstram o quanto os pais adotivos precisam estar receptivos para acolher seu filho de uma forma amorosa e compreensiva. Lidar inadequadamente (de forma agressiva ou não acolhendo as demandas emocionais da criança) com essa demanda pode trazer prejuízos à adaptação familiar. Partindo da premissa de que a adoção possibilita a reconstrução da identidade da criança pelo estabelecimento de um bom relacionamento com os novos pais, os 
afetos do cotidiano são componentes básicos para o crescimento de um vínculo amoroso (Maldonado, 1989).

Com relação à falta de limites apresentada pelas crianças e adolescentes no início da nova convivência, de acordo com Weber (2008), é comum que pais adotivos se sintam receosos e sem saber como lidar com algumas reações das crianças e/ou dos adolescentes recém-integrados à família. Além disso, do ponto de vista do comportamento, muitas vezes é exigida da criança que chega por adoção uma conduta mais correta do que a de qualquer outra criança, como se o fato de ter ganho uma família significasse a retribuição de docilidade, educação e bom comportamento imediatos. Quando os pais adotivos, a partir de uma idealização do projeto adotivo, esperam atitudes adequadas e resultados rápidos submetendo a criança a exigências exageradas que não podem ser correspondidas, isso pode produzir um total desajuste em sua conduta (Silva, 2004; Kirch \& Copatti, 2014). Tais questões podem contribuir para uma possível devolução ou interrupção no processo de adoção.

No que concerne à saúde física e mental, em estudo de Cavalcante, Magalhães e Ponte (2009) com 287 crianças em acolhimento institucional se constatou que $49,47 \%$ apresentavam doenças, deficiências e lesões corporais quando do seu encaminhamento ao abrigo. Em relação ao período de permanência na instituição, verificou-se que $42,5 \%$ das crianças contraíram doenças infectocontagiosas e 18,8\% manifestaram problemas de ordem emocional. Isso porque crianças que vivenciam o acolhimento institucional são oriundas geralmente de famílias com renda, moradia e escolaridade precárias, ficando expostas, desde o nascimento, a privações e maus-tra- tos nos primeiros anos de vida (Silva, 2004; Siqueira \& Dell'Aglio, 2006; Cavalcante, Magalhães \& Reis, 2014).

Foi possível observar, no presente estudo, grande preocupação dos adotantes em sanar com urgência as dificuldades apresentadas inicialmente pelos filhos. Isso pode se dar devido ao fato de que se espera dos pais a socialização da criança, os cuidados com a saúde, assim como toda atenção necessária para proporcionar equilíbrio e bem-estar aos seus filhos (Barroso \& Machado, 2010). Assim, quando uma adoção acontece, é função da família adotiva buscar meios para o atendimento necessário da criança ou adolescente visando ao restabelecimento de sua saúde.

Quando falamos em relacionamento entre adotantes e adotandos, percebemos que todos os indivíduos que vivenciam essa realidade passam pela adaptação, pelo ajustamento de uma nova situação, não sendo algo exclusivo de um ou de outro (Andrei, 2001; Dias, Silva, \& Fonseca, 2008).

O momento de inserção no novo ambiente familiar traz consigo a concretização da adoção normalmente implicando perdas, lutos e rompimentos (Silva et al., 2017). Ressalta-se que o acompanhamento do período de estágio de convivência pela equipe psicossocial do judiciário vem sendo considerada como essencial na supervisão do período de colocação na família substituta e ao longo do estágio de convivência (Merçon-Vargas, Rosa, \& Dell'Aglio, 2014; Nabinger, 2010; Weber, 2003), uma vez que estudos nacionais e internacionais apontam para a complexidade desta etapa (Alonso, 2012; Levy, Pinho, \& Faria, 2009, Simmel, 2007; Sturgees \& Selwyn, 2007; Weber, 2003). Esse período é denominado por Costa e Rosseti-Ferreira (2007) como a entrada no "limbo", por 
se tratar de um momento frágil, de construção de vínculos onde todos os envolvidos sabem da possibilidade da devolução da criança à instituição.

No que se refere à categoria do comportamento sexualizado apresentado pelas crianças ou adolescentes, o fato de ter sido verificado em cinco dos oito estudos analisados vem corroborar outras pesquisas que apontam o número crescente desse tipo de violência em âmbito mundial (Bittencourt, 1995; Gauderer \& Morgado, 1992; Paixão, 2010).

Ainda com relação ao comportamento sexualizado dos adotandos, esta ação pode ser entendida como uma manifestação de um sofrimento psíquico que está em busca de uma reorganização interna (Costa \& Teixeira, 2017). A violência sexual é uma das formas mais graves de violência, e é justamente no interior da família a sua maior incidência. Pesquisas apontam que as pessoas que possuem vínculo de parentesco ou que estão ligadas aos cuidados e responsabilidades com as crianças e adolescentes são as que mais perpetram tais atos (Habizang et al., 2006; Koller \& De Antoni, 2004).

Sobre a dificuldade de relacionamento entre irmãos, é importante ressaltar que a chegada de um novo membro na família, independentemente de vir por meio de gestação ou pela adoção, altera não só a rotina diária como a maneira como os familiares se relacionam. A presença de uma nova criança ou adolescente traz em relação àquela que já existia no seio familiar uma série de sentimentos antagônicos, os quais motivam conflitos não só com o recém-chegado, mas com as figuras parentais. Contudo, na relação de pais e filhos, existe uma hierarquia preestabelecida, diferentemente da vinculação fraterna. Assim, ampliam-se as possibilidades de troca entre irmãos, facilitando as relações familiares (Muniz \& Féres-Carneiro, 2012).

Otuka, Comin e Santos (2009) consideram que é também na convivência entre irmãos que se desenvolve o sentimento social, fundamental para o desenvolvimento do caráter. Em sua pesquisa, foi possível identificar que, em casos de famílias em que o filho adotivo é criado junto ao filho biológico, sentimentos ambivalentes podem aparecer aos pais, pois existe a preocupação de não produzir diferenças entre os filhos. Os pais possuem um papel fundamental para a adaptação dos filhos, pois podem buscar estratégias para aproximá-los, uni-los, uma vez que o vínculo fraterno apresenta um sentimento de pertencimento que reflete na interação entre irmãos e nas relações sociais de um modo geral (Goldsmit \& Féres-Carneiro, 2011).

No que diz respeito ao afastamento dos familiares e/ou amigos, é necessário ressaltar o quanto a rede social é significativa nas relações extra e intrafamiliares. Por rede social entendemos o sistema composto por vários objetos sociais (pessoas), funções (atividades dessas pessoas) e situações (contexto), as quais oferecem apoio não só material mas também emocional (Dessen \& Braz, 2000).

Dias (2006) constatou que o apoio dos familiares e amigos foi considerado um fator decisivo para o sucesso da adoção. Mais recentemente, Machado, Feres-Carneiro e Magalhães (2015) mostraram que a família extensa não tem interferência direta na tomada de decisão pela adoção, contudo, sua função apareceu como fundamental na inserção da criança adotada na família após a adoção. Pode-se inferir, portanto, como é difícil para as famílias adotivas enfrentarem o afastamento de seus entes queridos. Ainda que hoje a adoção tenha conquistado um 
reconhecimento, ela ainda é permeada por crenças e preconceitos (Goes, 2014) e, quando esse preconceito é verificado no meio familiar ou no ciclo de amizades, pode acarretar escolhas, rompimentos e até mesmo o fracasso da adoção.

No que se refere à relação com a família biológica/bagagem histórica da criança, deve-se atentar que quando se fala em adoção de crianças maiores, antes de mais nada se está falando de crianças e adolescentes que tiveram um passado junto às suas famílias biológicas ou a programas de acolhimento institucionais. Nesta modalidade de adoção virá uma criança com uma história e lembranças do passado. O simples fato de expressar sua vivência, que na maioria das vezes foi constituída de abandonos, violências e negligências, pode ser o suficiente para trazer medo, insegurança, desconforto aos adotantes que, geralmente, não sabem como agir diante de uma realidade tão diferente daquela a que estão acostumados e também por despertar receios quanto até que ponto tal vivência poderia influenciar em seu comportamento e atitudes (Souza \& Casanova, 2012).

Realizar uma adoção de crianças maiores ou adolescentes é, portanto, renunciar ao sonho de ver o filho passar por todas as fases da infância, é começar a acompanhar seu desenvolvimento tendo perdido o acompanhamento de alguns anos. Mas é preciso saber que, mesmo não tendo participado de seu passado, terá de aceitá-lo. Isso requer maturidade, equilíbrio e esclarecimento por parte dos adotantes. Mas se faz possível e é capaz de causar bons resultados (Diniz, 1993). Algumas pesquisas destacam que existe maior estabilidade emocional e maturidade em quem realiza adoções de crianças maiores e que isso pode ser determinado pela idade dos adotantes, que em média é mais elevada do que os adotantes de crianças mais jovens, a chamada adoção convencional, o fato de a maioria já possuir filhos e ter um nível socioeconômico mais elevado (Ebrahim, 2001).

Observa-se, por conseguinte, que a adoção de crianças maiores ou adolescentes requer maior preparo dos adotantes, maturidade, estabilidade emocional e altruísmo. Conhecer o passado da criança ajuda os adotantes a conhecer seu filho e conversar sobre ele pode auxiliá-la a preencher lacunas de tempo ou de situações não compreendidas (Costa \& Rossetti-Ferreira, 2007), facilitando a adaptação e, consequentemente, a adoção.

Com relação à sobrecarga de tarefas, essa é uma subcategoria que pode parecer de pequena relevância se comparada às demais. No entanto, ela pode tomar uma proporção grandiosa e se tornar difícil de administrar da mesma maneira que as outras, prejudicando a adaptação e, em última instância, a adoção. Daí a importância de a família buscar estratégias para suplantá-la. Estudos que investigaram as relações familiares e a parentalidade apontaram que, com a sobrecarga de trabalho, a necessidade da negociação de tarefas aparece como o principal gerador de conflito entre os casais (Piccinini et al., 2007). Nesse mesmo caminho, Menezes e Lopes (2007) verificaram que as exigências e tarefas que o exercício da maternidade impõe às mulheres trazem para elas insatisfações com o casamento, gerando conflitos entre o casal. Estar consciente de que a rotina será alterada, que as responsabilidades que o casal tinha quando conviviam apenas entre os dois se somarão a muitas outras com o exercício da paternidade/maternidade e que dentre elas estarão presentes diariamente as muitas tarefas domésticas e os cuida- 
dos com os filhos, é essencial para que consigam lidar de maneira adequada com a transformação da conjugalidade para a parentalidade.

No que tange ao distanciamento do casal, apesar de ter sido verificado no presente estudo em pequena proporção, é um assunto que desperta indagações e precisa ser discutido. A relação conjugal e sua transição para a parentalidade é uma delas. Estudos apontam que a passagem por esses dois estágios é uma das mudanças mais significativas pelo qual o sistema familiar pode passar (Carter \& McGoldrick, 1995). Menezes e Lopes (2007) constataram que a transição para a parentalidade acarreta a diminuição da satisfação conjugal. Entretanto, apesar de perceberem que há um declínio em relação ao romance, observa-se um aumento no companheirismo e na parceria no período da transição conjugalidade/ parentalidade.

A transição para a parentalidade adotiva exige que os pais, além de assumirem agora papéis parentais e não mais vinculados somente à conjugalidade, quando pais pela primeira vez, também exige reconhecer como filho a criança gerada por outro. Para que isso ocorra, exige um tempo de reflexão e elaborações (Machado, Carneiro, \& Magalhães, 2015)

Tornar-se um casal é uma das transições mais complexas do ciclo de vida familiar. E a forma como o casal vivencia a sua relação conjugal vai ser importante na transição da conjugalidade para parentalidade (Belsky et al., 1983; Carter \& McGoldrick, 1995; Levy-Shiff, 1994), principalmente por representar um período de estresse, crise e alterações de papéis quando da chegada de um filho. Percebe-se, portanto, o quanto as relações humanas são complexas, sendo a família uma rede repleta de relações que se dife- rencia e exerce suas funções através de subsistemas (Minuchim, 1982). As mudanças ocorrem na família de um modo geral independente dessa criança e/ou adolescente chegar por meio gestacional ou pela via da adoção.

No que diz respeito às estratégias utilizadas para lidar com os desafios apresentados, observou-se que os adotantes se valeram de imposição de regras e limites, equilíbrio emocional, atendimento médico e/ou psicológico para superar problemas pré-existentes, castigos e/ou palmadas, reforço positivo sobre a adoção, atendimento psicológico para lidar com a adoção propriamente dita e apoio da família extensa.

A aceitação e o apoio da família extensa são condição de fundamental importância para que o sucesso da adoção aconteça. Família não é somente pais e mães, mas também avós, tios e primos, dentre outros. É com eles que os sonhos e as vitórias são compartilhadas e onde se busca refúgio nas derrotas. Quando uma criança é adotada é a família como um todo que conta, incluindo as gerações; se a criança que ali foi inserida não foi aceita, significa que o grupo familiar não a adotou (Souza \& Casanova, 2012).

A utilização de castigos e/ou palmadas foi uma prática verificada em quatro dos oito casos em análise. Pesquisas apontam a utilização de palmadas como um ato educacional legitimado entre os pais que entendem essa prática como "necessária" (Reis, 2015; Weber et al., 2004). Pelo que foi possível apreender, tal ação tem o cunho cultural e é utilizada de forma frequente com o objetivo de os adotantes obterem obediência dos adotandos. Nos casos em que já existiam filhos anteriores, tal prática lhes é extensiva, reforçando a ideia de que os castigos e as palmadas têm caráter educativo, tendo sido aprendido e, consequentemente, reproduzido. 
Nesse sentido é perceptivel a importância do atendimento psicológico e das estratégias para o bem-estar dos adotantes como forma de se vincular com o novo membro da família. Percebe-se, ainda, que os problemas encontrados não são característicos exclusivamente da adoção, mas sim da relação pais e filhos.

\section{CONSIDERAÇÕES FINAIS}

Constatou-se que a convivência familiar dos adotantes com os adotandos nos primeiros meses de adaptação foi bastante difícil. Este é um período de mudanças, adaptações, aprendizagem, incertezas, medos e conflitos. A adaptação verificada numa família adotiva, principalmente de crianças maiores e adolescentes, apresenta algumas especificidades e por isso precisa de atenção e acompanhamento das equipes técnicas do judiciário e demais profissionais. Contudo, sabe-se que encontrar dificuldades com a educação dos filhos é algo universal e ocorre que nas filiações adotivas existe uma tendência a extrapolar os aspectos do processo evolutivo infantil. Geralmente, crises pertinentes ao desenvolvimento normal de qualquer criança são confundidas como sendo "problemas da adoção" (Schettini, 2006).

Observou-se que, apesar dos desafios apontados pelos adotantes, houve sucesso na adaptação familiar; mais que isso, houve sucesso na adoção. A paciência, persistência, dedicação, a busca por ajuda profissional, o empenho e o desejo de que o projeto da adoção desse certo, aliados à vontade das crianças e dos adolescentes de terem uma família, foram alguns dos fatores que contribuíram para o êxito destas adoções.

\section{REFERÊNCIAS}

Alonso, E. (2012). Proceso de construcción de una familia adoptiva: relato de dos familias. Papers Infancia, 2, 1-25.

Andreil, D. C. (2001). Reflexões sobre a adoção tardia. In F. Freire (Org.), Abandono e adoção: contribuições para uma cultura da adoção (pp. 91-98). Curitiba: Terra dos Homens.

Associação dos Magistrados Brasileiros. (2014). Adoção Passo a Passo. Cartilha da adoção de Crianças e Adolescentes no Brasil. Recuperado de http://www.mprs.mp.br/areas/ infancia/arquivos/adocaopassoapassso.pdf

Barroso, R. G. \& Machado, C. (2010). Definições, dimensões e determinantes da parentalidade. Psychologica, 52(1), 211-229.

Belsky, J., Spanier G. B., \& Rovine, M. (1983). Stability and Change in Marriage across the Transition to Parenthood. Journal of Marriage and Family, 45(3), 567-577.

Bittencourt, C. B. F. (1995). Violência sexual contra crianças: implicações psicológicas. Pediatria Moderna, 31(3), 420-424.

Bardlin, L. (2000). Análise de conteúdo. Lisboa: Edições 70.

Cadastro Nacional de Adoção. (2018). Recuperado de http://www. cnj.jus.br/sistemas/infancia-e-juventude/20530-cadastro-nacional-deadocao-cna.

Carter, B. \& McGoldrick, M. (1995). As mudanças no ciclo de vida familiar - uma estrutura para a terapia familiar (2a ed.). Porto Alegre: Artes Médicas.

Carvalho, S. R., \& Ferreirra, M. R. P. (2000). Primeiro Guia de Adoção de crianças e adolescentes do Brasil. São Paulo: Winners Editorial. 
Cavalcante, L. I. C., Magalhães, C. M. C., \& Reis, D. C. (2014). Análise comparativa do perfil de crianças em acolhimento institucional nos anos de 2004 e 2009. Psico, 45(1), 90-99.

Cavalcante, L. I. C., Magallhães, C. M. C., \& Pontes, F. A. R. (2009). Processos de saúde-doença entre crianças institucionalizadas: uma visão ecológica. Ciência \& Saúde Coletiva, 14(2), 614-625.

Costa, N. R. A. \& Rossetti-Ferreira, M. C. (2007). Tornar-se Pai e Mãe em um processo de adoção tardia. $P s i$ cologia: Reflexão e Crítica, 20(3), 425-434.

Costa, S. F. \& Teixeira, S. (2017). "A história não tem de ser o destino": o risco psicossocial em crianças com famílias disfuncionais. Revista de Psicologia da Criança e do Adolescente, 7(1-2), 193-203.

Dessen, M. A. \& Braz, M. P. (2000). Rede Social de Apoio Durante Transições Familiares Decorrentes do Nascimento dos Filhos. Psicologia: Teoria e Pesquisa, 16(3), 221-231.

Dias, M. B. (2005). Manual de Direito das Famílias. Porto Alegre: Livraria do Advogado.

Dias, C. M. S. B. (2006). A importância da família extensa na adoção. In L. Schettini Filho \& S. S. M. Schettini (Eds.). Adoção, os vários lados dessa história (pp. 173-194). Recife: Bagaço.

Dias, C. M. S. B., Silva, R. V. B., \& Fonseca, C. M. S. M. S. (2008). A adoção de crianças maiores na perspectiva dos pais adotivos. Contextos clínicos, 1(1), 28-35.

Diniz, J. S. (1993). Este meu filho que eu não tive: a adoção e os seus problemas. Porto: Afrontamento.

Ebrahim, S. G. (2001). Adoção Tardia: altruísmo, maturidade e estabilidade emocional. Psicologia Reflexão e Crítica, 14(1), 73-80.
Festinger, T. (2012). After adoption: dissolution or permanence? Child Welfare, 81(3), 515-533.

Gauderer, C. E. \& Morgado, K. (1992). Abuso sexual na criança e no adolescente. Jornal de Pediatria, 68(8), 7-8.

Giacomozzi, A. In, Nicoletti, Mng \& Godinho, E. M. (2016). As representações sociais e as motivações para adoção de pretendentes brasileiros à adoção. Psychologica, 58(1), 41-64.

Ghirardi, M. L. A. M. (2009). A devolução de crianças adotadas: ruptura do laço familiar. Campo Belo, São Paulo. Recuperado de http://www.moreirajr.com.br/

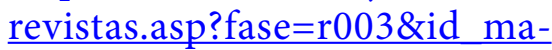
$\underline{\text { teria }=3988}$

Goes, A. E. D. (2014). Criança não é brinquedo! A devolução de crianças e adolescentes em processos adotivos.(Syn) thesis, 7(1), 85-93.

Gondim, A. Kr, Crispim, C. S., Fernandes, F. H. T., Rosendo, J. C., Brito, T. M. C. D., Oliveira, U. B. D., \& Nakano, T. D. C. (2008). Motivação dos pais para a prática da adoção. Boletim de Psicologia, 129(78), 161-170. Goldsmit, R. \& Féres-Carneiro, T. (2011). Relação Fraterna: constituição do sujeito e formação do laço social. Psicologia USP, 22(4), 771-787.

Habizang, L. F., Azevedo, G. A., Koller, S. H., \& Machado, P. X. (2006). Fatores de risco e de proteção na rede de atendimento à crianças e adolescentes vítimas de violência sexual. Psicologia: Reflexão e Crítica, 19(3), 379-386.

Kirch, A. T. \& Copatti, L. C. (2014). Criança e adolescente: a problemática da adoção e posterior devolução às casas de acolhimento. Prisma Jurídico, 13(1), 13-36. 
Koller, S. H. \& De Antoni, C. (2004). Violência intrafamiliar: uma visão ecológica. In S. H. Koller (Ed.), Ecologia do Desenvolvimento Humano: pesquisa e intervenção no Brasil (pp. 293-310). São Paulo: Casa do Psicólogo.

Lei n. 12.010, de 03 de agosto de 2009. (2009). Dispõe sobre adoção. Recuperado em 26 de junho 2018, http:// www.planalto.gov.br/ccivil 03/ ato20072010/2009/lei/112010.htm

Levy, L., Pinho, P. G., \& Faria, M. M. (2009). "Família é muito sofrimento": um estudo de casos de "devolução" de crianças. Psico, 40(1), 58-63.

Levy-Shiff, R. (1994). Individual and contextual correlates of marital change across the transition to parenthood. Developmental Psychology, 30(4), 591-601.

Levinzon, G. K. (2004). Adoção: clínica psicanalítica. São Paulo: Casa do Psicólogo.

Machado, R. N., Féres-Carneiro, T.s \& Magalhães, A. S. (2015). Parentalidade adotiva: Contextualizando a escolha. Psico, 46(4), 442-451.

Maldonado, M. T. (1989). Maternidade e paternidade. Petrópolis, RJ: Vozes. Mariano, F. N. (2004). O cenário jurídico: a análise de processos de adoção do município de Ribeirão Preto (1991-2000). Dissertação de Mestrado, Programa de Pós-graduação em Psicologia, Universidade de São Paulo, Ribeirão Preto, SP.

Menezes, C. C. \& Lopes, R. C. S. (2007). Relação conjugal na transição para a parentalidade: gestação até dezoito meses do bebê. Psico-USF, 12(1), 83-93.

Mello, M. M. \& Luz, K. G. (2016). Adoção tardia: contribuições do projeto DNA da alma de Farroupilha/ RS. Saúde e Desenvolvimento $\mathrm{Hu}$ mano, 4(1), 37-46.
Minuchim, S. (1982). Famílias: funcionamento e tratamento. Porto Alegre; Artes Médicas.

Muniz, A. A. M. \& Férez-Carneiro, T. F. (2012). Função fraterna: reflexões a partir do filme Príncipe das Marés. Psicologia em Revista, 18(1), 41-56.

Nabinger, S. (2010). Adoção: o encontro de duas histórias. Santo Ângelo, RS: FURI.

Otuka, L. K., Scorsolini-Comin, F., \& Santos, M. A. (2009). A Configuração dos vínculos na adoção: uma atualização no contexto latino-americano. Revista Brasileira de Desenvolvimento Humano, 19(3), 475-486.

Paixão, A. C. W. (2010). Análise das políticas públicas de enfrentamento da violência sexual infanto-juvenil. Saúde e Sociedade, 19(1), 114-126.

Peres, R. \& Santos, M. A. (2005). Considerações gerais e orientações práticas acerca do empregode estudos de caso na pesquisa científica em Psicologia. Interações, 10(20), 109-126.

Piccinini, C. A., Pereira, C. R. R., Marin, A. H., \& Lopes, R. C. S. (2007). O nascimento do segundo filho e as relações familiares. Psicologia: Teoria e Pesquisa, 23(3), 253-261.

Reis, A. G. (2015). Práticas educativas e violência: uma reflexão crítica. Trabalho de Conclusão de Curso de Especialização de Psicologia, Universidade Federal do Rio Grande do Sul (UFRGS). Porto Alegre. Recuperado de http://hdl.handle. $\underline{\text { net } / 10183 / 141408}$

Riede, J. E., \& Sartori, G. L. Z. (2017). Adoção e os fatores de risco: do afeto à devolução das crianças e adolescentes. Perspectiva, 37(138), p.143-154.

Santos, M. A., Raspantini, R. L., Silva, L. A. Moreira, \& Escrivão, M. V. (2003). Dos laços de sangue aos laços de 
ternura: o processo de construção da parentalidade nos pais adotivos. Psic: revista da Vetor Editora, 4(1), 14-21.

Schettini, L. (Org.). (2006). Adoção: os vários lados dessa história. Recife: Bagaço.

Smith, S. L., Howard, J. A., Garnier, P. C., \& Ryan, S. D. (2006). Where are we now? A post-ASFA examination of adoption disruption. Adoption Quarterly, 9(4), 19-44.

Silva, J. A. (2009). Adoção de Crianças Maiores. Dissertação de Mestrado, Programa de Pós-graduação Psicologia. Pontifícia Universidade Católica de Minas Gerais, Belo Horizonte, MG.

Silva, P. S. D., Perez, L. C., Castellá Sarriera, J.g \& Frizzo, G. B. (2017). A equipe psicossocial na colocação da criança nos processos de adoção. Psicologia: Ciência e Profissão, 37(3), 608-623.

Silva, E. R. A. (Coord.). (2004). O direito à convivência familiar e comunitária: os abrigos para crianças e adolescentes no Brasil. Brasília, DF: Ipea/Conanda.

Silva, L., Nunes, C., \& Almeida, A. S. (2017). Complexidade da conceção de parentalidade em famílias adotivas. Revista PSICOLOGIA, 31(2), 198-201.

Simmel, C. (2007). Risk and protective factors contributing to the longitudinal psychosocial well-being of adopted foster children. Journal of Emotional and Behavioral Disorders, 15(4), 237-249.

Siqueira, A. C. \& Dell’Aglio, D. D. (2006). $\mathrm{O}$ impacto da institucionalização na infância e na adolescência: uma revisão da literatura. Psicologia \& Sociedade, 18(3), 71-80.

Souza, H. P. \& Casanova, R. P. S. (2012). Adoção: o amor faz o mundo girar mais rápido. Curitiba: Juruá.
Sturgess, W. \& Selwyn, J. (2007). Supporting the placements of children adopted out of care. Clinical Child Psychology and Psychiatry, 12(1), 13-28.

Trindade, J. (2004). Manual de Psicologia Jurídica. Porto Alegre: Livraria do Advogado.

Vargas, M. M. (1998). Adoção tardia: da família sonhada à família possível. São Paulo: Casa do Psicólogo.

Vargas, E. A. M., Rosa, E. M., \& Dell'Aglio, D. D. (2014). Adoção nacional e internacional: significados, motivações e processos de habilitação. $R e$ vista da SPAGESP, 15(2), 12-26.

Weber, L. N. D. (2008). Interações entre família e desenvolvimento. In L. N. D. Weber (Org.). Família e desenvolvimento: visões multidisciplinares (pp. 9-20). Curitiba: Juruá.

Weber, L. N. D. \& Cornélio, S. A. (1994). Filhos adotivos: Amores ou dissabores? In Sociedade Brasileira para o Progresso da Ciência (Org.), $46 a$ Reunião Anual para o Progresso da Ciência (p. 873), Vitória: SBPC.

Weber, L. N. D. \& Gagno, A. Pr (1995). Onde estão os vínculos afetivos das crianças institucionalizadas? In Caderno de Resumos do Congresso Latino-Americano de Psiquiatria da Infância e da Adolescência (p. 25). Curitiba.

Weber, L. N. D., Gagno, A. Pry Cornélio, S. A., \& Silva, M. L. (1994). Adoção: pré-conceitos, conceitos e pós-conceitos. In Sociedade Brasileira para o Progresso da Ciência (Org.), $46 a$ Reunião Anual para o Progresso da Ciência (p. 854), Vitória: SBPC.

Weber, L. N. D. (2003). Pais e filhos por adoção no Brasil. Características, expectativas e sentimentos. Curitiba, PR: Juruá.

Weber, L. N. D., Viezzer, A. Prs \& Brandenburg, 0. J. (2004). O uso de palmadas e surras como prática educativa. Estudos de Psicologia, 9(2), 227-237. 
ANGELITA DA COSTA PEIXOTO

Poder Judiciário de Santa Catarina, Florianópolis, SC, Brasil

E-mail: angelita.machado@tjsc.jus.br

\section{ANDRÉIA ISABEL GIACOMOZZI}

Universidade Federal de Santa Catarina - UFSC, Florianópolis, SC, Brasil E-mail: agiacomozzi@hotmail.com

\section{ANDRÉA BARBARÁ DA SILVA BOUSFIELD}

Universidade Federal de Santa Catarina - UFSC, Florianópolis, SC, Brasil E-mail: andreabs@gmail.com

\section{BRUNA BERRI}

Universidade Federal de Santa Catarina - UFSC, Florianópolis, SC, Brasil E-mail: brunaberri@hotmail.com

\section{JULIANA GOMES FIOROTT}

Universidade Federal de Santa Catarina - UFSC, Florianópolis, SC, Brasil E-mail: juliana.gomesfiorott@gmail.com 